\title{
Relationship between Organizational Culture, Transformational Leadership, Working Motivation to Organizational Commitment
}

\author{
A. Khalik ${ }^{1}$, Soewarto Hardhienata ${ }^{2}$, Widodo Sunaryo ${ }^{3}$ \\ Post Graduate Program, Universitas Pakuan Bogor, Indonesia
}

\begin{abstract}
The objective of this research is to determine the correlation between dependent variables of organization culture, transformational leadership, and job motivation with an independent variable; organizational commitment of lecturers in a state institute for Islamic study. The survey is executed on samples of 180 lecturers by proportional random sampling technique in Jambi, Indonesia. The research applies a Sequential Explanatory Design Mixed Method by conducting quantitative research first then followed by the qualitative research to obtain comprehensive output. The study both quantitatively and qualitatively reveals that there is a positive significant relationship among variables under the following distribution of coefficient of determination: organizational culture to lecturers' organizational commitment $=17 \%$, transformational leadership to lecturers' organizational commitment $=18 \%$, working motivation to lecturers' organizational commitment $=14 \%$ and when tested together it produces coefficient of correlation $=19 \%$ indicating the existence of other $81 \%$ variables not including in the model affecting factors affecting organizational commitment in a state institute for Islamic study's lecturers working environment.
\end{abstract}

Keywords: organization culture, transformational leadership, job motivation, organizational commitment.

\section{INTRODUCTION}

The functions of the 21st century higher education and college cannot be separated from the constellation pattern of changes and future life. The dynamics of the organization is currently moving very quickly as being triggered and accelerated by the development of the times. This progress provides various facilities but also demands serious attention and treatment in terms of human resources which is a reliable, creative and committed. The committed employee is one the factors that determines the success of achieving the objectives of an organization. Human resources committed to the organization provides a major influence on the successful achievement of objectives. Without the commitment from both of the decision-makers and employees the goal of the organization will be difficult to achieve. Commitment to the organization can be reflected in the execution of duties and functions in the implementation of the organization's daily program. One form of implementation of commitment to the organization is the treatment of time in the form of presence at the job site in order to provide excellent service including the participation in the committee on the activities of institutions and other related activities.

Based on the results of a preliminary survey of the 20 lecturers from State Institute for Islamic Study Sultan Taha Saifuddin in Jambi, Indonesia concerning organizational commitment, it is found that:

$32.5 \%$ of the lecturers surveyed showed indications of problems in terms of launching the organizational tasks and take the time to follow the programs of the organization;

$42.50 \%$ of the lecturers surveyed showed indications of problems in terms of job that requires responsibility and work in accordance with their duties and functions of the specified organizations;

$42.50 \%$ of the lecturers surveyed showed indications of problems in terms of devoting themselves solely on areas that provide many financial benefits and cross-checking the results for the sake of guaranteeing the service organization.

Based on the preliminary survey data above, it can be concluded that the condition of commitment to the organization in the respective institution is still low and needs improving. Based on the background and the results of the identification of the problem, the formulation of the problem is: 


\section{A. Khalik et al.}

1. Does organisational culture positively affect State Institute for Islamic Study lecturers' organizational commitment?

2. Does transformational leadership positively affect State Institute for Islamic Study lecturers' organizational commitment?

3. Does working motivation positively affect State Institute for Islamic Study lecturers' organizational commitment?

4. Do organisational culture, transformational leadership and working motivation altogether affect State Institute for Islamic Study lecturers' organizational commitment?

\section{LITERATURE REVIEW}

According to Cohen (2006), organisational commitment "as a research topic is important regardless of its setting because a better understanding of the phenomenon may help us to better understand the nature of the psychological process through which people choose to identify with different objects in their environment and how they find purpose in life". Allen and Meyer (2000) identify some variables as an antecedent of organizational commitment. This suggests the need for a research study that will determine the relationship between transformational leadership, personality and job satisfaction and organisational commitment. Various authors have discussed a possible theoretical link between organizational commitment and organisational culture. It appears as if organisational culture tends to influence employees' work effort and commitment directly through cultural values, and indirectly through human resources practices (Manetje, \& Martins, 2009). Findings by, Chatman, Caldwell and O'Reilly (1999) suggest that individuals who fit the organisational culture are those who are committed at a normative or value-based commitment dimension; while Nystrom (1993) states that a correlation between organisational culture and organisational commitment indicates that people who work in a strong culture feel more committed. It appears from the research that there is a link between Organizational Culture, Transformational Leadership, Working Motivation to Organizational Commitment; however, no evidence was found to suggest that similar research studies had been conducted among lecturers of State Institute for Islamic Study in Indonesia which notably the organizational culture and management practices are different from other public organization.

Organizational Culture stated by Jason A. Colquit, Jeffery A, Lepine and Michel J. Wessor (2009) that defines: "Organizational culture as the shared social knowledge within an organization regarding the rules, norms, and values that shape the atttitudes and behaviors of its employees ".

Based on the theories mentioned above, it can be synthesized that in school organization, organizational culture is a pattern of basic assumptions or basic philosophy agreed upon and developed at the school to be implemented and achieved.

Bernard M. Bass and Ronald E. Riggio (2006) defines transformational leadership as behavior which can stimulate and inspire followers to achieve results in the process of developing leadership skills, vision and goals given organization, to challenge itself to innovate, solve problems, and develop the ability of the leadership to subordinates through guiding, mentoring, ,challenging and supporting. "Transformational leaders, on the other hand, are then those who stimulate and inspire followers both in achieving extraordinary outcomes and developing their own leadership capacity".

Gary Yukl (2006) stated that transformational leadership is the behavior of a leader who is able to call on his followers moral values in their efforts to raise awareness of ethical issues and mobilize energy and resources to reform institutions. Factors associated with the above definition are: 1) communicating the vision, 2) expressive, 3) a risk taker and sacrificed himself, 4) communicating high expectations, 5) consistent behavior vision, 6) managing the respect of subordinates against leadership, 7) establishing the existence of a group or organization, 8) empowering subordinates.

Based on the theories mentioned above, it can be synthesized that transformational leadership is the behavior of a leader who can inspire subordinates (teachers) to commit to the vision of the school, communicating, motivating, directing, empowering subordinates, to be a model, developing the potential of subordinates as well as a new perspective in solving the problem. The dimensions and indicators are: 1) the influence of the ideal toward subordinates, 2) the inspiration that motivates, 3) intellectual stimulation, 4) treatment of subordinates, 5) communication skills, 6) the giver of challenge and support. 
Lambert Deckers (2010) states that motivation is "a description of motivation as the process by the which a person is moved into action. Motivation can originate from internal sources, described as biological and psychological variables, and from external sources, such as incentives and goals.

Paul E. Spector (2008) defines motivation as an internal state of a person which is associated with certain behaviors. One perspective to mention the relationship between motivation with the direction, intensity, persistence behavior at the same time. Directions refers to the selection of the specific behavior of a large number of existing behavior. Intensity refers to the amount of effort for someone to do their job. Persistence refers to the ongoing relationship.

Based on some theories above, it can be synthesized that motivation of teachers are energetic impulse from within themselves as well as influences from outside that encourage activity and give the power to determine the intensity and resistance to achieve the purpose. The dimensions and indicators of teachers' work motivation is:

a. Intrinsic dimension which consists of indicators: 1) the encouragement of hard work in doing the job, 2) the drive to achieve the work, 3) the spirit of achieving success, b. Extrinsic dimension which consists of indicators: 1) collaboration with the personnel in the work environment, 2) the award of the environment, 3) support for leadership. Based on above description, the following hypothesis is formulated:

1. Organisational culture is positively related to State Institute for Islamic Study lecturers' organizational commitment.

2. Transformational Leadership is positively related to State Institute for Islamic Study lecturers' organizational commitment

3. Working motivation is positively related to State Institute for Islamic Study lecturers' organizational commitment.

4. Organizational culture, transformational leadership and working motivation altogether are positively related to State Institute for Islamic Study lecturers' organizational commitment.

\section{Methodology}

This study applies Sequential Explanatory Design Mixed Method where quantiative study is ahead of qualitative study to examine the relationship between variables tested in the study using three independent variables through data obtained from questionnaires. The independent variable is Organizational Culture $\left(\mathrm{X}_{1}\right)$, Transformational Leadership $\left(\mathrm{X}_{2}\right)$, and Working Motivation $\left(\mathrm{X}_{3}\right)$, while the dependent variable is the Lecturers' Organizational Commitment (Y).

The relationship among variables in the study described in Fig.1 below:

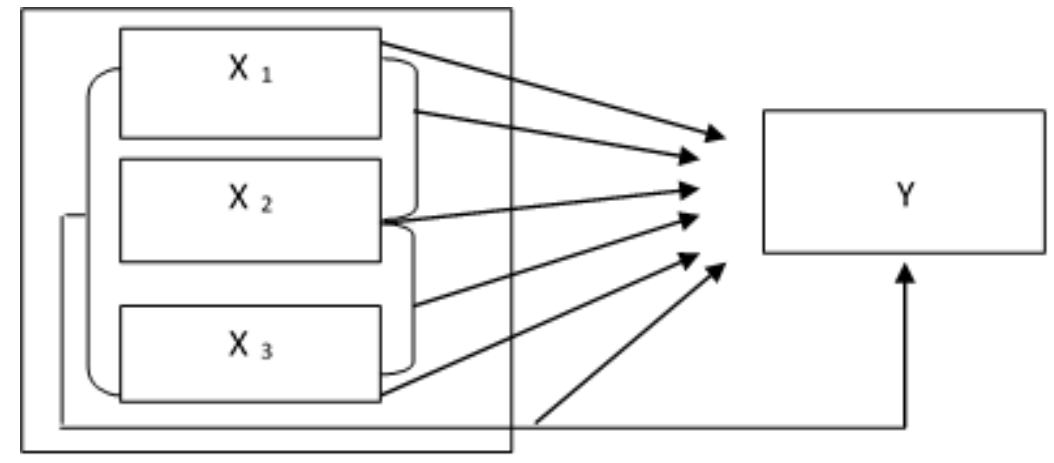

Figure1. Theoretical framework.

where,

$\mathrm{Y}=$ Organizational Commitment

$\mathrm{X}_{1}=$ Organizational Culture

$\mathrm{X}_{2}=$ Transformational Leadership

$\mathrm{X}_{3}=$ Organizational Commitment 


\section{A. Khalik et al.}

The population of this study is all 180 lecturers of state institute for Islamic study in the city of Jambi, Indonesia. Hypothesis testing is conducted by using regression analysis to determine the influence of one or more independent variables on the dependent variable. The linearity assumption are prerequisites to proceed to further test. Hypothesis testing is performed at a significance level of 0.05 .

Qualitative study for the purpose of confirmation was performed through observation and interview to key informant as well as conducting focus group discussion with department head and lecturers.

\section{RESUlt AND DISCUSSION}

The lecturers of the selected organisations were asked to participate in the survey by responding their opinions for four different measures in organizational culture, leadership, transformational leadership and organizational commitment. The linearity test is performed with F-test. Data is linear as the value of each variable is above the critical value for F-test.

\subsection{Organizational Culture and Lecturers' Organizational Commitment}

In order to test whether data from organizational culture and lecturers' organizational commitment are linear, F-test has been conducted. Since the F value as shown in table 1 is higher than the critical value of $\mathrm{F}$ table, we can proceed to test the alternate hypothesis if organizational culture is positively related to lecturers' organizational commitment within state institute for Islamic study in Jambi, Indonesia. The strength of association of organizational culture $\left(\mathrm{X}_{1}\right)$ to teacher's innovativeness. $(\mathrm{Y})$ is observable from coefficient correlation $\left(\mathrm{r}_{\mathrm{x} 1}\right)=0.42$.

Tabel 1. Linearity test and coefficient of correlation of organizational culture $\left(X_{1}\right)$ to lecturers' organizational commitment $(Y)$

\begin{tabular}{|c|c|c|c|c|c|}
\hline Observation & $\mathbf{R}$ & $\mathbf{R}^{\mathbf{2}}$ & $\mathbf{F}_{\text {-test }}$ & $\mathbf{F}_{\text {-tabel }} \boldsymbol{\alpha}$ & \multirow{2}{*}{ Conclusion } \\
\cline { 1 - 3 } & $\mathbf{R}_{\mathbf{x} 1}$ & $\mathrm{r}_{\mathbf{x} 1}^{2}$ & $\mathbf{F}_{\mathbf{x} 1}$ & 0.05 & \\
\hline 180 & 0.42 & 0.17 & 37.15 & 3.89 & Significant \\
\hline
\end{tabular}

$\mathrm{F}_{\text {test }}=37.15$ is above critical value where $\mathrm{F}_{\text {-tabel }}$ for $(\square=0.05)$ is 3.89 indicating that the data is linear and eligible for the next process. Coefficient of correlation $\left(\mathrm{r}_{\mathrm{x} 1}\right)=0.42$ indicates a medium positive relationship between organizational culture and lecturers' organizational commitment. Coefficient of determination $\left(\mathrm{r}^{2}{ }_{\mathrm{x}} 1\right)=0.17$ indicates that contribution of organizational culture to lecturers' organizational commitment is $17 \%$.

\subsection{Transformational Leadership and Lecturers' Organizational Commitment}

To test whether data from transformational leadership and lecturers' organizational commitment are linear, F-test has been conducted. The higher F value as shown in table 2 compared to the critical value of $\mathrm{F}$ table indicates the appropriateness of the model to test the alternate hypothesis if transformational leadership is positively related to lecturers' organizational commitment within state institute for Islamic study in Jambi, Indonesia. The strength of association of transformational leadership $\left(\mathrm{X}_{2}\right)$ to lecturers' organizational commitment $(\mathrm{Y})$ is observable from coefficient correlation $\left(\mathrm{r}_{\mathrm{x} 2}\right)=0.425$.

Tabel 2. Linearity test and coefficient of correlation of transformational leadership $\left(X_{2}\right)$ to lecturers' organizational commitment $(Y)$

\begin{tabular}{|c|c|c|c|c|c|}
\hline Observation & $\mathbf{R}$ & $\mathbf{R}^{\mathbf{2}}$ & $\mathbf{F}_{\text {-test }}$ & $\mathbf{F}_{\text {-tabel }} \alpha$ & \multirow{2}{*}{ Conclusion } \\
\cline { 1 - 3 } & $\mathbf{R}_{\mathbf{x} 2}$ & $\mathrm{r}_{\mathbf{x} 2}^{2}$ & $\mathbf{F}_{\mathbf{x} 2}$ & 0.05 & \\
\hline 180 & 0.43 & 0.18 & 37.15 & 3.89 & Significant \\
\hline
\end{tabular}

The table shows that $\mathrm{F}_{\text {test }}=37.15$ is above critical value where $\mathrm{F}_{\text {-tabel }}$ for $(\square=0.05)$ is 3.89 indicating that the data is linear and eligible for the next process. Coefficient of correlation $\left(\mathrm{r}_{\mathrm{x} 2}\right)=0.43$ indicates a moderate positive relationship between transformational leadership and lecturers' organizational commitment. Coefficient of determination $\left(\mathrm{r}_{\mathrm{x}}^{2} 2\right)=0.18$ indicates that contribution of transformational leadership to lecturers' organizational commitment is $18 \%$ while the rest $82 \%$ is determined by other factors not included in the model. This small figure may due to the fact that the leader does not apply the proper leadership style within the state institute for Islamic study organization.

\subsection{Working Motivation and Lecturers' Organizational Commitment}

Similar to previous model, to identify if data from working motivation and teachers' innovativeness are linear, F-test has been conducted. The higher F value as shown in table 3 compared to the critical 

Organizational Commitment

value of $\mathrm{F}$ table indicates the appropriateness of the model to test the alternate hypothesis if working motivation is positively related to lecturers' organizational commitment within state institute for Islamic study in Jambi, Indonesia. The strength of association of working motivation $\left(\mathrm{X}_{3}\right)$ to lecturers' organizational commitment $(\mathrm{Y})$ is observable from coefficient correlation $\left(\mathrm{r}_{\mathrm{x} 3}\right)=0.37$.

Tabel 3. Linearity test and coefficient of correlation of work satisfaction $\left(X_{3}\right)$ to lecturers' organizational commitment $(Y)$

\begin{tabular}{|c|c|c|c|c|c|}
\hline Observation & $\mathbf{R}$ & $\mathbf{R}^{\mathbf{2}}$ & $\mathbf{F}_{\text {-test }}$ & $\mathbf{F}_{\text {-tabel }} \alpha$ & \multirow{2}{*}{ Conclusion } \\
\cline { 1 - 3 } & $\mathbf{R}_{\mathbf{x} 3}$ & $\mathrm{r}_{\mathbf{x} 3}^{2}$ & $\mathbf{F}_{\mathbf{x} 2}$ & 0.05 & \\
\hline 180 & 0.37 & 0.14 & 37.15 & 3.89 & Significant \\
\cline { 1 - 3 }
\end{tabular}

The table shows that $\mathrm{F}_{\text {test }}=37.15$ is above critical value where $\mathrm{F}_{\text {-tabel }}$ for $(\square=0.05)$ is 3.89 indicating that the data is linear and eligible for the next process. Coefficient of correlation $\left(\mathrm{r}_{\mathrm{x} 2}\right)=0.37$ indicates a moderate positive relationship between working motivation and lecturers' organizational commitment. Coefficient of determination $\left(\mathrm{r}^{2}{ }_{\mathrm{x} 3}\right)=0.14$ indicates that contribution of working motivation to lecturers' organizational commitment is $14 \%$ while the rest $86 \%$ is determined by other factors not included in the model.

\subsection{Organizational Culture, Transformational Leadership and Working Motivation to Lecturers' Organizational Commitment}

When tested together the model is specified as:

$\hat{\mathrm{Y}}=\mathrm{b}_{0}+\mathrm{b}_{1} \mathrm{X}_{1}+\mathrm{b}_{2} \mathrm{X}_{2}+\mathrm{b}_{3} \mathrm{X}_{3}$

Where:

$\hat{\mathrm{Y}}=$ Organizational Commitment

$\mathrm{b}_{0}=$ Constant

$\mathrm{b}_{1}, \mathrm{~b}_{2}, \mathrm{~b}_{3}=$ regression coeficient

$\mathrm{X}_{1}=$ Organizational Culture

$\mathrm{X}_{2}=$ Transformational Leadership

$\mathrm{X}_{3}=$ Working Motivation

Tabel 4. Multiple Regression Analysis Summary

\begin{tabular}{|c|c|c|c|c|c|c|c|}
\hline Model & $\beta$ & $\mathbf{R}$ & $\mathbf{R}^{2}$ & $\mathbf{F}_{\text {-test }}$ & $\mathbf{F}_{\text {-tabel }} \alpha$ & Conclusion \\
\hline & & & & & \multicolumn{1}{|c|}{$\mathbf{0 . 0 5}$} & \\
\hline Constant & & & & 13.97 & 2.65 & Significant \\
\hline Organizational Culture & 0 & & & & & & \\
\hline $\begin{array}{c}\text { Transformational } \\
\text { Leadership }\end{array}$ & 0.2 & 0.43 & 0.19 & & & & \\
\hline Working Motivation & 0.1 & & & & & & \\
\hline
\end{tabular}

Tables 4 show the results of multiple regression analysis. The table reports a significant $\mathrm{F}$ statistic, indicating that the model has strong prediction strength $(\mathrm{F}=13.97, \mathrm{p}<0.05)$. As further shown in Table 4, all variables altogether are weakly correlated to lecturers' organizational commitment as shown by coefficient of correlation $=0.43$ and only $19 \%$ of the variation in determination of lecturers' organizational commitment is explained by the model $(\mathrm{R}$ Square $=0.19)$.

The model derives the following equation: $\hat{Y}=72.594+0.004 \mathrm{X}_{1}+0.270 \mathrm{X}_{2}+0.153 \mathrm{X}_{3}$.

Observing the value of regression coefficient from the highest to the lowest, this model confirms that organizational culture $\left(\mathrm{X}_{1}\right)$ as the weakest variable in determining the teachers' innovativeness and transformational leadership $\left(\mathrm{X}_{2}\right)$ is the strongest followed by working motivation $\left(\mathrm{X}_{3}\right)$.

Similarly, based on the analysis of qualitative research interviews, observation and documentation in the state institute for Islamic study in Jambi, Indonesia, it is known that there found the tendency of a positive relationship between organizational culture, transformational leadership, teachers working motivation together with lecturers' organizational commitment. This suggests a strengthening of 


\section{A. Khalik et al.}

quantitative research results of hypothesis testing that there is a functional relationship between organizational culture, transformational leadership and motivation of lecturers to organizational commitment. This way, any increase in scores of organizational culture, transformational leadership, and motivation of lecturers will increase organizational commitment

\section{CONCLUSION}

The findings prove that there is a positive and significant relationship between the organizational culture on lecturers' organizational commitment, transformational leadership on lecturers' organizational commitment and working motivation on lecturers' organizational commitment among lecturers working in state institute for Islamic study located in Jambi, Indonesia. With particular reference to initial design of the interaction among variables, the results showed that the contribution of organizational culture variable on lecturers' organizational commitment is $17 \%$, transformational leadership is $18 \%$, and working motivation is $14 \%$ indicating the highest individual contribution to the commitment of lecturers is transformational leadership. When combined together, contribution of the three variables of organizational culture, transformational leadership and working motivation achieve only $19 \%$ indicating the contribution of other variables not included in the model to predict lecturers' organizational commitment reach $81 \%$ indicating this model is of low goodness of fit. Therefore, other researchers wishing to conduct similar research must include other variables related to organizational commitment. Those variables might be the school facilities and infrastructure, job satisfaction of lecturers, the working environment, working discipline, intellectual and emotional intelligence, and achievement motivation.

\section{REFERENCES}

Allen, Natalie J., and John P. Meyer. "Construct validation in organizational behavior research: The case of organizational commitment." In Problems and solutions in human assessment, pp. 285314. Springer US, 2000.

Bernard M. Bass \& Ronald E. Riggio, Transformational Leadership,(New Jersey: Lawrence Erlbaum associates, Publishers, 2006), pp. 3-6.

Chatman, Jennifer A., David F. Caldwell, and Charles A. O'Reilly. "Managerial personality and performance: A semi-idiographic approach." Journal of Research in Personality 33, no. 4 (1999): 514-545.

Cohen, Aaron. "The relationship between multiple commitments and organizational citizenship behavior in Arab and Jewish culture." Journal of Vocational behavior 69, no. 1, 2006, pp. 105118.

Colquitt, J., Lepine, J. A., \& Wesson, M. J., Organizational behavior: Improving performance and commitment in the workplace. McGraw-Hill/Irwin, 2009, ch.2 pp. 66-70.

Gary Yukl, Leadership in Organizations, (New York: Pearson Education International, 2006), pp.251 $\& 254$

Jason A. Colquit., Jeffery A, Lepine and Michel J Wessor, Organizational Improving Performance and Commitmen in the Workplace, (New York McGraw Hill/Irwin, 2009), pp. 546-551

John R. Schermerhorn, James G. Hunt, Richard N. Osborn, Mary Uhl-Bien, Organizational Behaviour, (USA: John Willey \& Sons, Inc., 2010), pp.376-379.

Lambert Deckers, Motivation: Biological, Psychological, and Environmental, (New Jersey: Allyn \& Bacon, Pearson Education, Inc.,2010), pp.1.

Manetje, O., and Nico Martins. "The relationship between organisational culture and organisational commitment." Southern African Business Review 13, no. 1, 2009, pp. 87- 111.

Nystrom, Paul C. "Organizational cultures, strategies, and commitments in health care organizations." Health Care Management Review 18, no. 1, 1993, pp.43-49.

Paul E. Spector, Industrial Organizational Psychology; Research and Practice, Fith Edition, (USA: John Wiley\& Sons, Inc., 2008), pp.200

Wood, Wallace, Zeppane, Schermerhorn, Hunt, Osborn, Organizational Behaviour: A Global Perspective, (Sydney: John Wiley \& Sons Australia, Ltd., 2001), pp. 611-614. 